\title{
El intercambio académico entre México y América Latina durante el cardenismo. Problemas, debates y actores
}

Academic Exchange between Mexico and Latin America during the Cárdenas regime. Problems, Debates, and Actors

\section{Sebastián Rivera Mir}

El Colegio Mexiquense

sebastianriveramir@gmail.com

\section{Resumen}

El presente artículo se propone explorar los principales cuestionamientos historiográficos que se pueden plantear en torno al intercambio académico internacional realizado durante la presidencia de Lázaro Cárdenas. Este primer acercamiento busca construir un marco analítico desde el cual observar esta temática, y en lugar de esbozar resultados finales concluyentes, en las siguientes páginas se intenta profundizar en las preguntas que dicho proceso plantea a la historia de la educación. Este tema ha sido una de las constantes en el ámbito universitario, sin embargo, la historiografía escasamente ha profundizado en aquél. Por este motivo, se recurre a un abanico metodológico y de fuentes para analizar cuáles son las potencialidades de emprender su estudio de manera sistemática.

Palabras clave: intercambio académico, Lázaro Cárdenas, Historia transnacional de la educación, México, América Latina.

\section{Abstract}

The purpose of this article is to explore the historiographical problems around the topic of international academic exchange during the Lázaro Cárdenas presidential period. It is a first approach in the search of an analytical framework to observe and understand this phenomenon. Rather than offering some conclusive results, in the following pages / will sketch the questions and possibilities for studying it and the challenges this study poses to the history of education. Whereas academic exchange is a constant in the Mexican university system, there is very little historical research into it. The present 
paper proposes a different array of sources and methodologies to undertake its examination in a systematic manner.

Keywords: academic exchange, Lázaro Cárdenas, transnational history of education, Mexico, Latin America.

\section{Introducción}

El intercambio académico ha sido un tema que ha recibido escasa atención por parte de los historiadores mexicanos. Sin embargo, al mismo tiempo ha sido un mecanismo presente en la mayoría de los procesos educativos que se han enfrentado en el país. Al parecer, su presencia cotidiana y de largo plazo, en lugar de convocar el interés por parte de los investigadores, ha terminado por hacerlo invisible para los mismos académicos inmersos en un sistema de intercambios.

El presente artículo se propone un primer acercamiento a las problemáticas y los debates que se han desplegado a partir de su implementación. En ese sentido es un texto que se enfoca más en construir preguntas de investigación, que en encontrar respuestas. Y con el fin de delimitar el análisis, se ha optado por circunscribir el objeto de estudio al periodo cardenista. Esta opción no es azarosa, sino al contrario, como espero problematizar a lo largo de las siguientes páginas, esta etapa estuvo atravesada por un proceso de complejización del intercambio que se proyectó no sólo en los espacios educativos, sino también en los ámbitos diplomáticos, políticos y culturales en un sentido amplio. La educación socialista propugnada por Cárdenas fue quizás uno de los procesos que desplegó un mayor impacto a nivel continental, pero no fue lo único. A esto debemos sumar, desde el auge en la producción editorial hasta la creación de un espacio panamericano que en ocasiones respaldó los esfuerzos locales, pasando por la notoria ampliación del sistema universitario. El dinamismo mexicano en el plano educativo durante el cardenismo fue un momento propicio para el intercambio académico. ${ }^{1}$

Las relaciones de México con el resto de América Latina son, de igual modo, un mirador privilegiado para vislumbrar los esfuerzos que se produjeron en este ámbito. A diferencia de los desequilibrios que contemplaríamos en los nexos con Europa o Estados Unidos, en el caso latinoamericano el escenario estuvo marcado por la construcción de vínculos más sutiles, tanto verticales como horizontales. La importancia que adquirió México para el sur del continente nos exige repensar las dinámicas centro/periferia, desarrollo/subdesarrollo, o

\footnotetext{
${ }^{1}$ En este texto se entiende este concepto como un proceso que implicó el intercambio de profesores, de estudiantes y también de materiales impresos. Por un motivo metodológico, el énfasis está puesto en los dos primeros elementos, dejando el intercambio de impresos para un análisis por separado.
} 
todas las posturas dicotómicas que suelen aplicarse al momento de analizar este tipo de temáticas.

Antes de continuar, cabe advertir que el intercambio académico no sólo significó la llegada a México de profesores, estudiantes o materiales educativos, sino también involucró el establecimiento de un diálogo entre los distintos actores implicados. ${ }^{2}$ Estos contactos envolvieron debates, discusiones, críticas y rechazos, y además no siempre tuvieron los resultados que presupuestaron sus gestores. La creatividad de los sujetos, su capacidad de intervenir de manera autónoma en los procesos empujó a que muchos de los planes estatales o institucionales debieron ser consensuados o negociados antes de realizarse. Finalmente, las propuestas detrás del intercambio académico, sus éxitos y sus fracasos, siempre dependieron de las decisiones de los sujetos de carne y hueso. Por esta interacción en particular, me parece tan relevante hacer una historia del intercambio académico.

Para comenzar a analizar quiénes fueron los actores de estos intercambios, veamos, en primer lugar, cómo la historiografía ha enfrentado este tipo de problemáticas.

\section{Historiografía en construcción}

Hace algunos años, en un artículo planteaba la escasez de textos que se enfocaran en este tema (Rivera, 2012: 185-241). La situación no ha variado mucho si sostenemos una mirada restringida sobre el asunto. Los trabajos de Mílada Bazant (1987: 739-758) y Aimer Granados (2007: 103-124) continúan siendo los principales esfuerzos historiográficos por analizar los alcances que tuvo el intercambio académico en los procesos culturales e intelectuales mexicanos. ${ }^{3}$ Ambos autores aportan miradas particulares sobre las experiencias de los becarios y sobre las redes que generaron los implicados, respectivamente.

Ahora bien, si ampliamos el espectro, en los últimos años se ha producido un énfasis en temáticas que, si bien no apuntan directamente al intercambio académico, son cruciales para comprender su importancia como parte de los entramados políticos, culturales y educativos. ${ }^{4}$ En primer lugar, se han fortalecido los trabajos que estudian la cooperación intelectual. En este caso, por ejemplo, el libro de Alexandra Pita (2014), Educar para la paz. México y la cooperación intelectual internacional, 1922-1948, sin duda ha abierto una veta de análisis

\footnotetext{
${ }^{2}$ En parte a esta distinción se refiere Andrés H. Reggiani (2007) cuando explica el paso de la peregrinatio academica, base del funcionamiento de las universidades tradicionales, a los modernos flujos académicos internacionales.

${ }^{3}$ Esto contrasta con los esfuerzos analíticos que otras disciplinas han llevado a cabo en los últimos años. Las actividades y publicaciones de la Red sobre Internacionalización y Movilidades Académicas y Científicas (RIMAC) son un claro ejemplo de la importancia que estas temáticas han adquirido en la actualidad.

${ }^{4}$ Sobre esta perspectiva y su amplitud de potencialidades analíticas, conviene revisar el libro coordinado por Charle et al.(2006), aunque no se detiene en casos mexicanos.
} 
relevante, no sólo combinando la diplomacia cultural con los factores intelectuales, sino destacando la educación como una apuesta clave, más allá de lo que denominaríamos vínculos culturales e intelectuales (Herrera, 2009). Esta centralidad de lo educativo, en el caso de Pita, para evitar la guerra y en contra de los nacionalismos, me parece precisamente un llamado de atención insoslayable al momento de considerar los planes de intercambio entre México y América Latina.

En segundo lugar, en la última década se ha desarrollado un corpus importante de trabajos que ha profundizado en las relaciones culturales de México con América Latina, pero que, a diferencia de periodos previos, ahora enfatizan en aquellos actores que no pertenecen necesariamente al ámbito estatal u oficial (Pulido, 2017: 133-169). Una diplomacia cultural, en un sentido amplio, se ha instalado en estos nuevos estudios. La obra de Martín Bergel (2015), por ejemplo, es uno de estos casos. Pero más importante para este artículo exploratorio es el libro de Amelia M. Kiddle (2016), Mexico's Relations with Latin America during the Cárdenas Era. Para esta autora, lo educativo fue precisamente lo que marcó el proyecto latinoamericanista del cardenismo, fue lo que le permitió abrir puertas en ciertos lugares y clausurarlas en otros. Mientras algunos autores han planteado que la mirada de Lázaro Cárdenas no estuvo puesta en el sur del continente, el documentado texto de Kiddle cuestiona, sin sobredimensionar, esta supuesta falta de atención.

Por otra parte, desde una perspectiva metodológica, retomando a Erving Goffman, destaca la importancia de los rituales de interacción como mecanismo para construir la reputación de México en diversas áreas de la diplomacia. Obviamente, el intercambio académico no se comprende sin considerarlos parte de estos rituales de interacción. La presencia física, la circulación de correspondencia, el relato de viajes, el flujo de publicaciones fueron parte de este proceso, el cual, en muchos sentidos, correspondió a ciertos rituales de interacción que es necesario desentrelazar.

Finalmente, una tercera línea de investigación que se ha fortalecido en los últimos años corresponde a los estudios generados a partir de las propuestas poscoloniales que buscan, principalmente, analizar la relación académica-intelectual entre Estados Unidos y América Latina. Algunos pocos textos se han concentrado en México, pero en este caso quisiera destacar un libro aparecido hace poco y que se refiere a la construcción de las nuevas disciplinas científico-sociales durante la primera mitad del siglo Xx. Me refiero en particular a la propuesta de Ricardo D. Salvatore (2016), Disciplinary Conquest. U.S. Scholars in South America, 1900-1945 (véase también Salvatore, 2007). Lo relevante del texto para comenzar a investigar sobre el intercambio académico es que nos permite tener un contexto más amplio sobre los procesos educativos y científicos que se desarrollaban en el continente. De igual modo, nos posibilita preguntarnos hasta qué punto las dinámicas educativas puestas en movimiento por México a través del intercambio académico se entrelazaron con las necesidades de 
construir un conocimiento local y autónomo respecto de su vecino del norte, pero que, además, mantuviera una capacidad de intercambio o traductibilidad a otros espacios latinoamericanos. Esta doble tensión fue quizás uno de primeros desafíos para comprender la importancia que adquirió el país y que justificó la presencia de estudiantes y profesores de toda América Latina en las aulas mexicanas.

\section{Por qué México como destino}

A nivel de políticas estatales, la "escuela socialista" pareciera ser una de las propuestas que mayor interés provocó en el extranjero, especialmente por su impacto en el ámbito rural. Según Kiddle (2016), su vinculación con procesos anticlericales y de secularización potenció la polarización a través del continente. Sin embargo, éste requiere ser contemplado con ciertos matices. Los distintos procesos englobados en las modificaciones educativas cardenistas permitieron al país recuperar cierta posición privilegiada que había construido gracias a las misiones estudiantiles carrancistas (Pulido, 2017) y a las reformas impulsadas por el otrora Maestro de la Juventud latinoamericana, José Vasconcelos (Rivera, 2012). Fue precisamente este reencauzamiento lo que permitió a Lázaro Cárdenas volverse un actor importante en los debates locales y en las prácticas de los grupos de izquierda del continente, ya que no sólo proponía un cierto socialismo, sino que esto se complementaba con el ataque a los sectores más reaccionarios de la sociedad. Por supuesto, por "socialista" se entendían cosas muy diversas en el contexto mexicano, como lo demuestran los estudios recientes, y si insertamos la discusión a nivel continental, tenemos una verdadera constelación de posibilidades. Estas dudas sobre el contenido realmente existente de lo socialista también sirvió de acicate para que estudiantes, profesores, pedagogos, sindicalistas de la educación y otros actores se sintieran atraídos por conocer la experiencia mexicana. ${ }^{5}$ De hecho, las autoridades de México fueron activas en la difusión de sus planes educativos, incluso a veces esto les trajo problemas. Mientras en Colombia, Paraguay y algunos países de Centroamérica el cardenismo fue visto como un proyecto cuasi comunista, en otros países, como Chile, la intromisión en los sindicatos educativos locales por parte de los enviados mexicanos generó un rechazo no tanto de índole ideológica, sino acusando directamente intervencionismo. Por supuesto que, al igual que la cuestionada visita de José Vasconcelos a comienzos de los años veinte, que significó la llegada de Gabriela Mistral a México, los cuestionamientos en contra de embajadores y

\footnotetext{
${ }^{5}$ Algo similar ha planteado John Britton para el caso de los estadounidenses que decidieron venir a México: "The lack of a consistent definition of socialism within the Cárdenas administration and the often rambling commentary of U.S. sympathizers led some students of Mexican history to conclude that the revolutionary image of these years was more rhetoric and intention that policy and accomplishment" (Britton, 1995: 144).
} 
enviados sindicales mexicanos se convirtieron en un puente para que la izquierda chilena mirara hacia el país del norte (Yankelevich, 2003; Zuleta, 2008).

Mucho menos trabajado por la historiografía latinoamericanista, no así por la historia de la educación, se encuentra otro proceso que fue crucial para generar los marcos institucionales del intercambio académico: la ampliación del sistema universitario (Piñera, 2011; Rangel, 1983; Latapí, coord., 2003). ${ }^{6}$ Por mencionar algunos casos, en 1932 las escuelas libres adquirieron la posibilidad de revalidar y emitir títulos profesionales; en 1936, se fundaron la Universidad Obrera y el Instituto Politécnico Nacional; en 1937, se reabrió la Universidad de Guadalajara ${ }^{7}$ y en Sinaloa, el Colegio Civil Rosales pasó a denominarse Universidad Socialista del Noroeste; en 1938 abrió sus puertas la Escuela Nacional de Antropología e Historia; en 1938, fue el turno de La Casa de España en México (que un año después se convirtió en El Colegio de México); y en 1940 se abrió la Universidad Veracruzana. En la Universidad Nacional Autónoma de México (UNAM) se comenzaron a consolidar proyectos que dieron cierto estatus a determinadas disciplinas.

En este contexto, surgieron nuevas facultades y se crearon los institutos de Física, de Matemáticas y de Biología (Padua, 2003). Desde sus escritos en el diario oficial El Nacional, en la sección "Temas antropológicos", el estudiante cubano Jorge A. Vivó planteaba, sobre el Instituto Politécnico Nacional y su carrera de Antropología, que "México, superando el miedo reacio a grandes reformas universitarias que aún existen en América Latina, hace un esfuerzo digno de mayor loa, organizando estos cursos que no sólo deben ser acogidos con entusiasmo por el estudiantado nacional, sino también por el de los países hermanos de raza que tanta atención prestan a la obra social que aquí se realiza".

A este esfuerzo se sumaron organismos especializados, dependientes de la SEP, que trataron de reorganizar el sistema en su conjunto, por ejemplo, el Consejo Nacional de Educación Superior y de la Investigación Científica, o posteriormente el Consejo Nacional de Educación Superior. ${ }^{9}$ Este impulso se explica, según Marta Eugenia García Ugarte, por el

\footnotetext{
${ }^{6}$ La construcción de la institucionalidad pareciera ser precisamente uno de los aspectos particulares del periodo. Mientras en sus orígenes medievales los intercambios académicos obedecían a decisiones o intereses personales, la tendencia a largo plazo fue precisamente la construcción de mecanismos que despersonalizaran este tipo de relación educativa (Charle et al., 2006).

${ }^{7}$ Del conflicto que se había mantenido en esta ciudad, también surgió en este periodo la primera institución privada del país, la Universidad Autónoma de Guadalajara, vinculada a la derecha clerical.

8 "La antropología en el Politécnico", El Nacional, $1^{\circ}$ de febrero de 1939, p. 4. La recuperación de la idea de "hermanos de raza" por parte del cubano parece no haber sido casual. En el ámbito de la antropología, la presencia de extranjeros, especialmente estadounidenses, comenzaba a motivar duras críticas por parte de los sectores conservadores (De la Peña, 1996).

${ }^{9}$ A esto debemos agregar también los cambios en la labor editorial del Estado, a través de la creación del Departamento Autónomo de Publicidad y Propaganda (DAPP), la empresa Productora e Importadora de Papeles S.A. (PIPSA), cambios en los Talleres Gráficos de la Nación, entre otros. El resultado final, según Engracia Loyo (1984), fue que el Estado mexicano se transformó en uno de los principales impresores de libros del continente.
} 
interés gubernamental de controlar políticamente el nuevo escenario y además "por suprimir radicalmente el carácter de monopolio y privilegio de las clases acomodadas que la educación superior ha tenido hasta hoy como consecuencia de las organización económica y social de nuestro país, y de la subordinación de los gobiernos a las exigencias de las minorías poseedoras de la riqueza y el saber" (García, 2017: 75). ${ }^{10}$ Por supuesto, detrás de estas palabras también estaba latente el conflicto que mantenía el gobierno con la UNAM, por el control de la enseñanza secundaria, entre otras situaciones. Aunque este enfrentamiento había bajado de intensidad, después del proceso de autonomización y la llegada de Fernando Ocaranza a la rectoría, el cardenismo no contaba con la institución para sus proyectos y, en algunos casos, se convirtió en un lugar de resguardo para la oposición conservadora (González, 1984: 154-163).

¿Cuál fue la relación de este nuevo esquema universitario a nivel nacional con la presencia en México de académicos y estudiantes extranjeros y latinoamericanos? En algunos casos, el apoyo mutuo fue evidente y ha recibido la atención de los investigadores, como en La Casa de España en México, pero éste no fue el único esquema de participación que se desarrolló. En el caso del Instituto Politécnico Nacional, la propia Secretaría de Relaciones Exteriores se encargó de propiciar la llegada de profesores que fueran capaces de llenar las nuevas plazas académicas. ${ }^{11}$ En el caso de la ENAH, se optó por la conversión de los alumnos de la primera generación en profesores de las siguientes promociones. Los cubanos Alberto Ruz Lhuillier, Calixta Guiteras y Jorge A. Vivó aprovecharon su experiencia y se transformaron en estudiantes/profesores en esta primera etapa (Izquierdo y Day, 2015). En la Universidad Obrera, la presencia de colombianos, chilenos, hondureños, dominicanos, bolivianos, entre otros, la dotó desde un comienzo de un sentido latinoamericanista. ${ }^{12}$

Este proceso tuvo evidentemente su contraparte. Volviendo a la disputa de la UNAM y los gobiernos posrevolucionarios, encontramos el caso del Instituto Hispano Mexicano "Juan Ruiz de Alarcón”, relacionado con los emigrados españoles, al igual que El Colegio de México. Sin embargo, éste no logró superar los problemas que la Universidad Nacional puso a su funcionamiento. Aunque la mayoría de las investigaciones han enfatizado las disputas inter-

\footnotetext{
${ }^{10}$ La autora retoma un texto de El Nacional, el periódico oficialista, para justificar su argumento (véase "Será creado el Consejo Nacional de Educación Superior y de la Investigación Científica a iniciativa del señor presidente", El Nacional, 28 de septiembre de 1935, p. 1.

11 "El Consulado General de México en Nueva York remite a la Secretaría de Relaciones Exteriores informes de artículos de prensa acerca de la invitación que hace el gobierno de México a profesores extranjeros para impartir enseñanza en el Instituto Politécnico Nacional", 1938, Archivo Histórico de la Secretaría de Relaciones Exteriores Genaro Estrada (AHSRE), Fondo Asuntos Diplomáticos, expediente III-374-7; "La Legación de México en Quito, Ecuador, informa a la Secretaría de Relaciones Exteriores que el señor ingeniero Max Forter, profesor de la Universidad Central del Ecuador solicita que el gobierno mexicano contrate sus servicios como profesor politécnico en México", 1938, AHSRE, Fondo Asuntos Diplomáticos, expediente III-379-14.

12 "Carta de estudiantes latinoamericanos de la Universidad Obrera a Vicente Lombardo Toledano", 8 de enero de 1938, FHVLT, id. 17557, leg. 306.
} 
nas del propio exilio español, Marta Eugenia García Ugarte propone una lectura asociada a los conflictos interuniversitarios. A su juicio, desde la UNAM, "se ponía énfasis en que autorizaba una institución de estudios 'para extranjeros' que violaba la Constitución del país, con el agravante de que demostraba desconocer la situación educativa de México, puesto que era bien sabido por todos que lo que sobraba en el país eran abogados" (García, 2017: 78). El conflicto tenía que ver con que las carreras que dictaría el nuevo Instituto competirían directamente por los puestos gubernamentales, que las autoridades de la UNAM consideraban el espacio laboral de sus egresados. El resultado a corto plazo fue que las presiones, incluyendo una reunión de su director, Pedro Martul Rey, con el rector de la UNAM, Gustavo Baz, fue que el Instituto se abstuvo de crear su escuela de Derecho. A mediano plazo, esta institución fue de las pocas iniciativas que no lograron consolidarse, y una vez que desapareció, sus profesores pasaron a formar parte del Colegio Madrid.

Detrás de estos debates observamos una dinámica clave para comprender la conformación del espacio universitario mexicano. La apuesta por basar el modelo en el "nacionalismo posrevolucionario" que permitiera el desarrollo local, debía dialogar con la necesidad de insertar internacionalmente la producción de conocimiento (Charle et al., 2006). En palabras de estos autores: "La internacionalización puede manifestarse como una estrategia deliberada, incrustada en el contexto de alta nacionalización y estrechamente vinculada con el mismo" (Charle et al., 2006: 8). Esta situación generó tensiones entre los sujetos implicados, y para el caso mexicano nos exige preguntarnos hasta qué punto impactó en las políticas educativas en torno al intercambio académico.

Finalmente, un último proceso que volvió la mirada de estudiantes y profesores latinoamericanos sobre México fue su relevancia a nivel de organismos panamericanos. ${ }^{13}$ Si bien esta línea de unidad continental había sido rechazada por algunos sectores debido al predominio estadounidense, a partir de la política de buena vecindad de Roosevelt, el nivel de cuestionamiento se fue apaciguando y lentamente fue reconvirtiéndose en el nuevo "interamericanismo". De igual modo, como algunos autores han planteado, desde América Latina se crearon proyectos que buscaron utilizar dicho escenario en beneficio de los intereses locales. ${ }^{14}$ Esta flexibilización de la mirada sobre las instituciones panamericanas permitió que se consolidaran, preponderantemente en México, algunas iniciativas educativas (Minor, 2016). Las estructuras culturales panamericanas, además, otorgaron becas y financiaron pasantías de profesores, especialmente para quienes querían incorporarse a algunos de sus espacios

\footnotetext{
${ }^{13}$ En el plano internacional, también es relevante mencionar que, según Reggiani (2007), entre 1936 y 1939, los flujos académicos hacia Europa se redujeron a sus niveles mínimos.

${ }^{14}$ Los distintos países latinoamericanos vieron con beneplácito cómo Estados Unidos utilizaba las reuniones panamericanas para demostrar su alejamiento de la política del big stick y también aprovecharon el espacio para desplegar sus propios proyectos nacionales (Cervo, 2008; Marichal, 2002).
} 
académicos, ya fuera el Instituto Panamericano de Historia y Geografía, el Instituto Indigenista Interamericano, entre otros. Cómo impactó el cambio de sentido del panamericanismo en los flujos del intercambio académico es otra pregunta relevante al momento de analizar esta situación, especialmente si consideramos que en esta materia no podemos perder de vista la relevancia de Estados Unidos.

Ahora volvamos sobre una de las preguntas planteadas al inicio de este artículo, quiénes fueron los sujetos implicados en este intercambio. Aunque para comenzar a responder en lugar de dar nombres, me parece preferible establecer algunos parámetros que nos permitan construir un perfil general de los sujetos en cuestión.

\section{¿Quiénes fueron?}

A fines de 1935, Jorge Eliecer Gaitán, rector de la Universidad Libre de Colombia en aquel momento, presentó de la siguiente forma a un par de becarios que venían a la Universidad Obrera a estudiar: "Son jóvenes de arresto, de una gran capacidad de trabajo, y entre los obreros de este país dos hombres de fervor y temperamento para la lucha revolucionaria. Van a esa capital a perfeccionar sus estudios en sus respectivos oficios becados por la Secretaría de Educación Pública de México. Además, estudiarán todos aquellos problemas sociales y económicos que a su clase se refieran con objeto de que al regresar a su país puedan poner estos al servicio de la revolución". ${ }^{15}$ Estas palabras recuperaron buena parte de la argumentación que solía usarse en el periodo para justificar la presencia de estudiantes o profesores latinoamericanos en las aulas mexicanas. Conceptualizaciones en torno a juventud, el compromiso revolucionario, el aprendizaje de la experiencia mexicana, solución de problemas sociales, fueron comunes para describir a los sujetos del intercambio académico. La pregunta que se puede proponer al respecto es cómo se relacionaron los discursos de los solicitantes con los requerimientos de los anfitriones, o en otras palabras hasta qué punto la coyuntura y las propuestas que estaban en boga en el país receptor impactaron en el lenguaje de quienes pedían becas o algún tipo de apoyo para estudiar. Aunque las dudas sobre esta situación atraviesan cualquier tipo de petición y no es solamente un problema asociado al intercambio académico, conviene preguntarse por este tipo de adecuaciones del lenguaje para volver sobre el análisis de los rituales de interacción que se propuso páginas atrás. En definitiva, ¿cuáles fueron los protocolos y las traducciones que debieron cumplir los implicados al momento de relacionarse con las autoridades y la sociedad del país huésped?

15 "Carta de Jorge Eliecer Gaitán a Vicente Lombardo Toledano", 13 de diciembre de 1935, FHVLT-Universidad Obrera, id. 15947, leg. 270, f. 1. En la carta presentaba a Heliodoro Guarín y Tulio Ramírez. 
De todas formas, más allá de la sinceridad de los discursos, las peticiones son una buena forma de comenzar a comprender quiénes fueron los implicados en dichos procesos. En este aspecto, la mayoría de los archivos de las entidades educativas y gubernamentales resguardan solicitudes. Por ejemplo, el Archivo Histórico de la Secretaría de Relaciones Exteriores Genaro Estrada (AHSRE) tiene casi setenta, entre colectivas e individuales, realizadas durante el periodo; en las cuales observamos que los solicitantes provenían de casi todos los países de América Latina, con la preeminencia de los centroamericanos. El país desde donde llegó una mayor cantidad de solicitudes fue Guatemala, seguido no muy de lejos por Panamá y Costa Rica (véase gráfica 1).

En el caso de las solicitudes recibidas directamente en las oficinas de la Presidencia, cuyo canal de llegada no coincidió con las rutas que siguieron las peticiones realizadas vía SRE, las

\section{Gráfica 1}

\section{Solicitudes de becas disponibles en el AHSRE (1934-1940)}

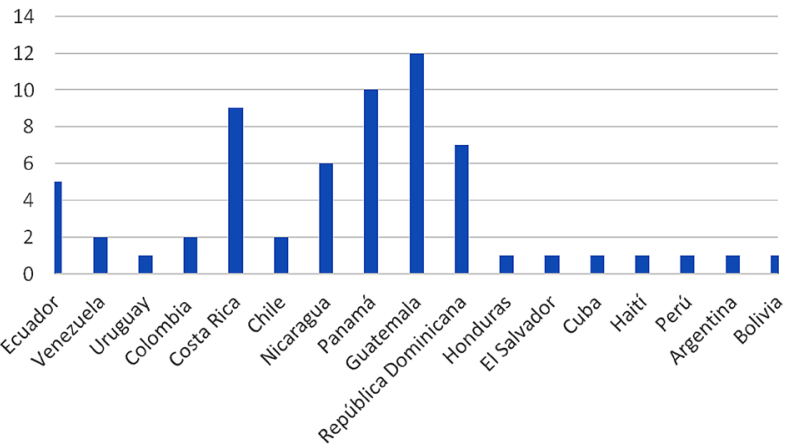

Fuente: Elaboración del autor con base en expedientes disponibles en el AHSRE.

cifras son similares (véase gráfica 2). Salvo la reducción drástica de la presencia panameña, la amplitud de países se mantiene, al igual que la preponderancia centroamericana. Aquí, sin embargo, debemos destacar la importancia que adquiría la figura del presidente Lázaro Cárdenas a nivel continental y la disposición de los estudiantes latinoamericanos para percibir cierta cercanía que les hacía escribir con la confianza en que sus cartas serían atendidas. Por supuesto, los canales que hicieron llegar las cartas al despacho presidencial se cruzaron con las dinámicas de la diplomacia regular, pero tal vez convendría caracterizarlos mejor como parte del amplio esfuerzo de actores e instituciones oficiosas que sobrepasaban los márgenes oficiales de Estado mexicano. 


\section{Gráfica 2 \\ Solicitudes enviadas al presidente Lázaro Cárdenas (1934-1940)}

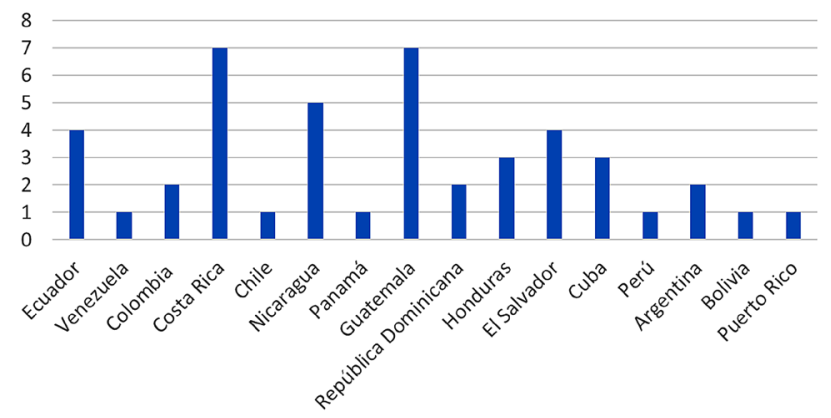

Fuente: Elaboración del autor con base en expedientes disponibles en AGN, Fondo presidente Lázaro Cárdenas.

De todas maneras, en ambos casos, la amplitud de solicitudes nos revela que el interés por llegar a México no fue un caso aislado, ni respondió solamente a la intención de estrechar o coronar relaciones diplomáticas amistosas. Aunque, de igual modo, posiblemente contó con el impulso de los espacios locales, ya fueran consulados, embajadas, agrupaciones sindicales, federaciones estudiantiles u otros organismos de solidaridad latinoamericanista. Por supuesto que la cifra de solicitudes no es sinónimo de quienes finalmente resultaron beneficiados por alguna beca o subsidio. ${ }^{16}$

El número total de favorecidos era una información desconocida por el propio gobierno y sus dependencias. Por ello, regularmente la SRE enviaba exhortos a distintas instituciones para que entregaran las nóminas de los estudiantes becados. En una de estas listas, pese a datar de 1942 (las anteriores son parciales y con vacíos, debido a instituciones que no informaron), pero con datos similares al periodo previo, ya que por el tiempo de duración de los programas las variaciones de un año a otro no son tan notorias, se restringen las becas entregadas a sólo once países, minimizando la presencia sudamericana (véase gráfica 3). Y sólo tres países centroamericanos suman casi dos tercios (44) del total de las becas entregadas (65). Esto es relevante, ya que permite contrastar las diferencias entre el impacto de

${ }^{16}$ Dados los vacíos en los archivos y su dispersión en distintas instituciones, la evaluación sobre la eficacia de las solicitudes posee un alto grado de inconsistencias. Sólo por mencionar una línea de análisis al respecto, cabe decir que, en comparación con las solicitudes realizadas por mexicanos, la tasa de éxito fue sustancialmente mayor, pues encontramos a casi 20 por ciento de los solicitantes extranjeros inscritos en alguna universidad mexicana. En el fondo de la sep disponible en el Archivo General de la Nación (AGN) se resguardan varios expedientes con más de setecientas fojas relacionados con las solicitudes de becas realizadas por mexicanos. Prácticamente todas fueron desechadas por falta de recursos. 


\section{Gráfica 3}

\section{Becarios latinoamericanos en México, según AHSRE (1942)}

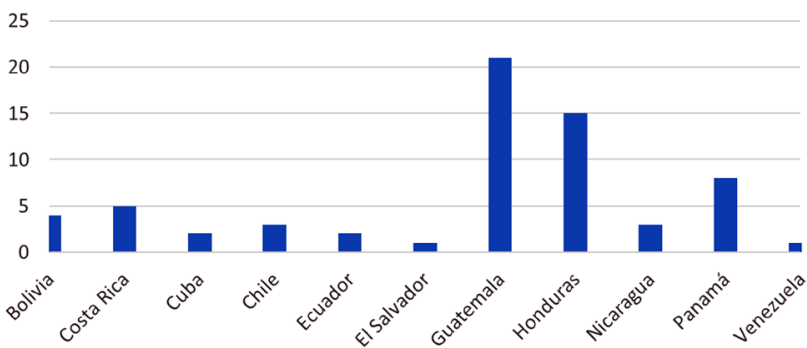

Fuente: elaboración del autor con base en "Lista de estudiantes extranjeros becados por nuestro gobierno" (abril de 1942), AHSRE, Fondo Asuntos diplomáticos, expediente III-243-15, sin foliar.

los discursos de propaganda, extendidos ampliamente a través del continente, y las políticas de apoyo educacional con una direccionalidad un poco más reducida. La entrega de becas a estudiantes extranjeros se concentró principalmente en la región que México consideraba prioritaria como zona de influencia directa (Buchenau, 1996).

De todas maneras, estas cifras no son definitivas, y consideran sólo a estudiantes becados por el gobierno mexicano, por lo que aún hay un margen importante considerando a quienes fueron becados por las propias instituciones, por sus gobiernos o que simplemente llegaron sin ningún tipo de ayuda. Por lo tanto, las cifras aquí mostradas, que reflejan sólo una tendencia, corresponden a un primer acercamiento, que indudablemente requiere mayor profundización y presenta un desafío metodológico y a nivel de fuentes para futuras investigaciones. Respecto de los profesores y las publicaciones, el rastreo de los números totales implica un desafío importante a nivel de fuentes, ya que en general no se manejan datos agregados al respecto.

En todo caso, otro dato interesante que entrega la revisión de los expedientes de la SRE y que no se presenta en el caso del Fondo presidente "Lázaro Cárdenas", es la importante participación en la solicitud y en el otorgamiento de becas a integrantes de fuerzas militares, especialmente desde los países centroamericanos. Si, como ya hemos visto, el intercambio académico ha recibido poca atención, el militar prácticamente no ha sido estudiado, por lo que su análisis abre perspectivas interesantes para comprender la experiencia de esos becarios y las relaciones que se establecieron con distintas fuerzas armadas, en el contexto de dictaduras militares que afectaban a la mayoría de los países de la región. Militares guatemaltecos pedían al gobierno mexicano realizar estudios en el país, mientras el gobierno de Cárdenas y el dictador Jorge Ubico se enfrentaban en torno a sus pretensiones sobre Belice. 
El régimen autoritario de El Salvador, dirigido por Maximiliano Hernández Martínez, la Nicaragua de Anastasio Somoza o la dictadura del general Tiburcio Carias, en Honduras, paradójicamente, mantuvieron un flujo casi constante de militares que se formaron en México, pese a la pública oposición del gobierno mexicano frente al carácter fascista de esos regímenes. Esto, por supuesto, supera los límites de los lazos estrictamente académicos, y pareciera situarnos de lleno en los escenarios de la geopolítica cardenista. Sin embargo, es relevante preguntarnos por la autonomía de lo académico, respecto de lo político, algo que difícilmente encontramos en el periodo estudiado.

En este mismo sentido, las persecuciones de las dictaduras también empujaron la llegada al país de estudiantes y profesores opositores. A algunos los rastreamos en los archivos de la SRE, pero en este caso fue más común que sus huellas quedaran en los acervos del Departamento de Investigaciones Políticas y Sociales (DGIPS) de la Secretaría de Gobernación. Los estudiantes salvadoreños que recalaron en la UNAM, Pedro Geoffroy Rivas, Julio Fernández Padilla, Antonio Asfura y Ricardo Jiménez Castillo, fueron vigilados regularmente por sus acciones violentas en contra de los funcionarios de la embajada y su involucramiento en la política nacional (Rivera, 2018). Geoffroy Rivas, por ejemplo, no sólo militaba en el Partido Comunista de México (PCM), sino que también se dedicaba a labores editoriales, lo que le permitía generar propaganda destinada a San Salvador. Como estudiante fue uno de los pocos en desarrollar una tesis sobre marxismo en la Facultad de Derecho y Ciencias Sociales (Geoffroy, 1937).17

Si este grupo de salvadoreños y otros continuaron con su proceso de politización, también hubo sectores que se caracterizaron por desligarse de lo político, incluso, pese a haber estado mucho más inmiscuidos en sus países de orígenes; tal fue el caso de la mayoría de los miembros de la Joven Cuba que llegaron a México a mediados de los años treinta. La hermana de Antonio Guiteras, ex secretario del Interior de Cuba y líder de dicha organización, Calixta, se concentró rápidamente en sus estudios de antropología y se mantuvo desligada de la política contingente. Lo mismo sucedió con otro cubano, Jorge A. Vivó, un alto cuadro de la Internacional Comunista en América Latina, quien, de igual modo, una vez instalado en México se desligó de la actividad militante. Para continuar con los cubanos, resulta interesante el caso de la pareja de Calixta Guiteras, Alberto Ruz Lhuillier, quien se desprendió tanto de su militancia, que en un homenaje que le realizó el Instituto de Investigaciones Filológicas, recopilando su bibliografía, no se menciona su prolífica escritura en las revistas de la izquierda, tanto cubanas como mexicanas, como por ejemplo, Frente a Frente (Ruz, 1936). ${ }^{18}$ En su caso,

\footnotetext{
${ }^{17}$ La tesis de su compatriota Julio Fernández Padilla (1939) fue defendida dos años después, y la de Antonio Asfura en 1941.

${ }^{18}$ Esta revista fue un particular espacio de encuentro para los latinoamericanos que pasaron por México durante el periodo.
} 
La disociación fue gradual: pasó de una agrupación que reivindicaba el uso de la violencia contra la dictadura, a la Liga de Escritores y Artistas Revolucionarios (LEAR), y después a las actividades organizativas en su núcleo de estudiantes. Este recorrido era desconocido por las autoridades de Gobernación, que frente a la vista a México de Fulgencio Batista, pusieron un cerco de vigilancia sobre los ex militantes de la Joven Cuba, temiendo que ellos realizaran algún atentado. ${ }^{19}$

Una característica más de los estudiantes y profesores que llegaron a México a vincularse a su sistema educativo fue su versatilidad en el plano de sus líneas de formación. Esto no fue un elemento particular sólo de este grupo, sino una situación que reflejaba el escenario de reconfiguración y especialización de las disciplinas en su conjunto. De hecho, como se vislumbró en el apartado anterior, los avances que desarrolló México en la consolidación de ciertos campos del conocimiento y su institucionalización en determinados programas, fue lo que atrajo el interés de algunos latinoamericanos. De cualquier modo, no fueron extraños los quiebres radicales en la trayectoria educativa de los implicados en el intercambio, y hubo casos en los que se saltaba de una formación en ciencias duras o teóricas a la investigación etnográfica, o mejor dicho, de la poesía a la economía. ${ }^{20}$

Antes de concluir este apartado, volvamos a los becarios presentados por Jorge Eliecer Gaitán. Ambos, Heliodoro Guarín y Tulio Ramírez, quienes pertenecían a una agrupación denominada Centro Nacional de Cultura Socialista de Colombia y habían obtenido sus becas después de un proceso de selección que no mostraba señales de corrupción o nepotismo, como sí podía ocurrir en otros casos (Kiddle, 2016). Sin embargo, una vez llegados a México surgieron problemas. Quien había gestionado los recursos había sido José Muñoz Cota, en ese entonces jefe del Departamento de Bellas Artes, y cuando los beneficiados Ilegaron al país, lo primero que hizo fue incluirlos en su ámbito político cercano. Los introdujo en la LEAR y también en el Grupo Unitario de Iniciativa y Acción, el espacio más apegado a Muñoz Cota. El problema surgió cuando este político se distanció de la LEAR ${ }^{21}$ y dejó a los colombianos en la necesidad de optar por cuál bando se decantaban. Heliodoro Guarín, antes de cualquier decisión, astutamente prefirió contarle la situación a Vicente Lombardo Toledano, director de la Universidad Obrera, ya que corría el riesgo de quedarse a la deriva: "Aunque la beca —explicó en una carta - a que me refiero no es sino por este año y vence el último del próximo mes de diciembre, yo aspiro a que se me conceda la misma beca para el año entrante. Mi futura petición se basará en que al terminar el año de estudios en la Escuela Superior de

19 "Sobre visita del coronel Fulgencio Batista a México", 1939, AGN, Fondo Dirección de Investigaciones Políticas y Sociales (DGIPS) caja 309, exp. 5.

${ }^{20}$ Véase el caso, por ejemplo, del estudiante de Economía de la unam, el salvadoreño Pedro Geoffroy Rivas (2008). Sus poemas quedaron en el olvido una vez que terminó su tesis sobre el materialismo histórico.

${ }^{21}$ Juan de la Cabada relata con detalle cuáles fueron los conflictos que terminaron con la relación entre los integrantes de la lear y el grupo de Muñoz Cota (Fierros, 2001). 
Comercio, y no haber terminado mis estudios en la Universidad Obrera, en las materias de Derecho Obrero y Karl Marx, es de absoluta necesidad la terminación de estos cursos para ir a mi país a ponerlos al servicio de las masas obrera y campesina; a las que pertenezco". 22

Lo interesante de este caso es que releva, en buena medida, que los profesores y estudiantes latinoamericanos se convirtieron en un mecanismo que prestigiaba los proyectos políticos locales y que, por otra parte, éstos fueron capaces de utilizar esta condición en su propio beneficio. La "orientación" que pidió Guarín a Lombardo Toledano también puede leerse como un medio de presión en el complejo escenario del México cardenista.

\section{Intercambio académico y exilio}

En general, la presencia del exilio latinoamericano en las instituciones educativas ha sido principalmente considerada desde un espectro político o, en muchos casos, de manera testimonial. Salvo el caso español (Hernández, 2012) y sudamericano durante los años setenta (Alfonso, 2015), escasamente se ha enfatizado desde una perspectiva educacional, y menos durante el cardenismo, por lo que me parece necesario cuestionarnos por las relaciones de intercambio académico que se establecieron a partir de este particular exilio.

En primer lugar, nos cuestionamos hasta qué punto se deben establecer continuidades entre el exilio y el intercambio académico. ${ }^{23}$ Estas experiencias, que parecen estar en el límite, contradictoriamente constituyeron durante el siglo xx parte del núcleo central de los intercambios académicos desarrollados entre México y América Latina. Esto, por un lado, significa reivindicar la continua historia de recepción de perseguidos por parte del gobierno mexicano y, al mismo tiempo, exponer la exclusión como mecanismo central de los regímenes latinoamericanos para mantenerse en el poder. Una vez en el país, la mayoría de los exiliados se incorporaron rápidamente a los espacios educativos, ya fuera por vocación o como un mecanismo de supervivencia. ${ }^{24}$ La lista de emigrados profesores o estudiantes durante el periodo 1934-1940 atraviesa a casi todos los países del sur del continente: va desde figuras intelectuales de exilios relativamente pequeños, como Aníbal Ponce, hasta grupos completos de centroamericanos unionistas, pasando incluso por "exiliados seriales", o aquellos que

22 "Carta de Heliodoro Guarín a VLT", 2 de octubre de 1936, FHVLT, id. 16543, leg. 283, f. 1.

${ }^{23}$ Esta perspectiva me parece que también sería fructífera para analizar la importancia de los exilios mexicanos en la circulación de saberes educativos, especialmente en el caso de los expulsados a Estados Unidos, quienes se incorporaron a sus universidades. Véanse, por ejemplo, algunos de los artículos de Latapí, coord. (2003), donde aparecen fugazmente este tipo de circunstancias.

${ }^{24}$ Aunque en el caso de los cubanos Juan Marinello y Ofelia Domínguez reconocían que sus salarios en escuelas preparatorias apenas les alcanzaban para sobrevivir (Rivera, 2018). 
constantemente vivieron en esta situación, como el sociólogo venezolano Salvador de la Plaza, quien tuvo al menos cuatro exilios en México durante el siglo Xx.

Aunque hagamos distinciones relevantes entre alguien beneficiado por el intercambio académico y una víctima de la persecución política o social que debe abandonar obligatoriamente su país, desde la historiografía se nos plantea una serie de problemas en torno a los límites entre ambas categorías. Por un lado, y como vimos en la caracterización inicial de estos sujetos, no podemos considerar a los beneficiarios de los intercambios como actores aislados del mundo político, de hecho, sin este factor no se comprende por qué se mueven de un país a otro. Por el otro, las redes de las que dependen, tanto en sus países de origen como en el lugar de recepción, coinciden con las estructuras que dan sostén a los emigrados. De igual modo, sus cotidianidades están marcadas por espacios de sociabilidad similares, o sea, en prácticamente todos los casos, las agrupaciones de latinoamericanos estuvieron integradas por emigrados y por profesores o estudiantes.

Por último, otro problema abierto por la dualidad intercambio/exilio es que, simplemente, los ejemplos nos demuestran que pasar de exiliado a profesor visitante, o de estudiante a exiliado, no fueron casos aislados, sino una situación común entre estos sujetos en busca de un lugar desde dónde generar conocimiento, en el sentido político que puede integrar este término. ${ }^{25}$ De todas formas, estos elementos no son temas agotados, y más bien deben ser parte de una agenda investigativa que permita comprender cómo ambas categorías se interrelacionaron en determinadas coyunturas particulares o, en otras palabras, cuándo y por qué un estudiante prefirió mostrarse más cercano al exilio o un emigrado optó por destacar su condición de académico o estudiante. En este sentido, el contexto político puesto en movimiento por Lázaro Cárdenas no sólo fue un escenario, sino que debe considerarse parte de estos procesos.

Desde otro ámbito, aunque durante el cardenismo no hubo experiencias que se proyectaran a largo plazo, el exilio latinoamericano intentó constituir espacios que institucionalizaran los intercambios que se desarrollaban a escala personal o a partir de pequeños grupos. Uno de estos esfuerzos fue la Casa de la América Latina, asociada a la Unión Revolucionaria Latinoamericana (URLA). Esta agrupación se fundó en 1937 y llegó a incluir a emigrados de la mayor parte del continente. ${ }^{26}$ Desde su misma fundación, se propuso la instauración de

\footnotetext{
${ }^{25}$ Miguel Zúñiga Cisneros, estudiante venezolano de medicina, llegó a México a un congreso internacional. Pero el gobierno de su país le impidió el regreso. Miguel Acosta Saignes, también venezolano, sufrió una situación similar. Algunos estudiantes salvadoreños en ciudad de México apedrearon la embajada de su país, viéndose enfrentados a la consiguiente persecución. Así, los casos de estudiantes que pasaron a transformarse en emigrados no fueron escasos (Rivera, 2018).

${ }^{26}$ En la urla hubo representantes de Argentina, Bolivia, Brasil, Chile, Colombia, Costa Rica, Cuba, Ecuador, El Salvador, Guatemala, Honduras, Nicaragua, Panamá, Paraguay, Perú, Puerto Rico, Santo Domingo, Uruguay y Venezuela. Su sede estuvo ubicada en Bucareli 80, letra o. Desde otra perspectiva política también se creó la Confederación de Estudiantes Antiimperialistas de América (CEADA).
} 
un organismo de cooperación intelectual, que posibilitara desplegar las relaciones académicas entre las instancias del país receptor y los recién llegados. Este proyecto se asoció a la creación de un Instituto de Investigaciones Latino Americanas, con su correspondiente biblioteca, y la publicación de una revista de circulación continental. El primero de los objetivos de esta instancia debería ser la "investigación y difusión de carácter científico, acerca de los problemas culturales, sociales, históricos, económicos y políticos de los países latinoamericanos" ${ }^{27}$ Para cumplir con sus lineamientos no sólo solicitaba el apoyo del gobierno y de la Confederación de Trabajadores de México, sino que proponía la necesidad de vincularse estrechamente con la sociedad mexicana. Un patronato con destacados intelectuales y políticos locales se encargaría de gestionar los recursos necesarios para la Casa de la América Latina.

Las gestiones fueron perdiendo impulso, en la medida que los emigrados y dirigentes de la URLA iban variando con los acontecimientos políticos en sus respectivos países de origen, y también debido al poco interés de las autoridades mexicanas, preocupadas por fortalecer otro tipo de iniciativas. De todas maneras, las actividades culturales y académicas asociadas a la URLA se mantuvieron hasta finales del sexenio cardenista y encontraron eco en algunas otras propuestas, como la Unión Democrática Centroamericana, que agrupaba a los exiliados de esta zona en particular. Aunque a pesar de referirse constantemente a la fraternidad latinoamericana, sus integrantes se preocuparon por diferenciarse de las redes y propuestas que realizaban los emigrados vinculados a la Alianza Popular Revolucionaria Americana (APRA). ${ }^{28}$ Este grupo también congregaba a un amplio abanico de emigrados latinoamericanos y desarrolló un esfuerzo por construir vínculos académicos (Melgar, 2003). Su estrategia, eso sí, no se detuvo en contemplar instituciones especializadas en este ámbito, optando por la inserción de sus militantes en los espacios educativos mexicanos, por lo que los encontramos en distintas universidades, desde Guadalajara o Michoacán, hasta las de más reciente formación en el Distrito Federal.

Aquí hay un tema interesante que destaca el historiador Ricardo Melgar Bao y que sería posible profundizar: me refiero a la fuerte distinción que aparece entre los estudiantes apristas y la generación un poco mayor que se insertó como profesores. Aunque el autor se concentra en este grupo, podemos ampliar la disyuntiva a otros sectores políticos, y establecer la necesidad de problematizar hasta qué punto se debe diferenciar entre la experiencia de estudiantes y profesores dentro de esta relación exilio/intercambio académico. Por ejemplo, el peruano Genaro Carnero Checa pasó un sinnúmero de dificultades para continuar sus estudios en México, incluyendo el trabajo forzado en un control migratorio de Veracruz

\footnotetext{
27 "Proyecto de la urla para establecer la Casa de la América Latina", 20 de febrero de 1939, FHVLT, id. 19529, leg. 347, f. 1.

28 Sobre estos enfrentamientos, véase, por ejemplo, "Memorándum de la urla sobre el Primer Congreso Juvenil Americano convocado por la sección juvenil del prm", 26 de noviembre de 1938, FHVLT, id. 19091, leg. 334.
} 
(Carnero, 1979). Mientras que, por otro lado, encontramos las dificultades de Aníbal Ponce, un intelectual argentino reconocido a nivel continental, para encontrar un espacio en el ámbito universitario, lo que lo llevó hasta Michoacán, sin poder desempeñarse en la Ciudad de México, como era su intención inicial. ${ }^{29}$ También se podrían haber tomado otros casos, en los que hubo menos complicaciones, pero lo relevante apunta a comprender que las dificultades que todos encontraron posiblemente significaron formas diversificadas de relacionarse con el país receptor. Esto exige explorar estas situaciones con detenimiento, sin caer en los lugares comunes de la hospitalidad generalizada y sin cálculos, con los que se tendió a ver la recepción en la historiografía (Gleizer, 2011).

\section{La gira de estudios y la propaganda del régimen}

Una práctica asociada al intercambio académico fue la organización de viajes colectivos o individuales de interesados en conocer la experiencia mexicana, sin incorporarse directamente a alguna institución local. Este tipo de excursiones se considerarían contactos superficiales, mas no por ello dejaban de ser consideradas relevantes en la articulación del intercambio académico y los planes propagandistas del gobierno. ${ }^{30}$ En palabras de Peter Schötler (2006), este tipo de contactos fueron claves para desempeñar un "trabajo en red", lo que a su vez da cuenta de los contornos y las estructuras implicadas en los procesos educativos.

En este caso, la cobertura de los medios de comunicación era una de las claves para lograr los objetivos gubernamentales, por lo que, en muchas ocasiones, los pasos cotidianos de estas giras quedaron registrados en sus páginas. Incluso, El Machete, periódico del PCM relativamente periférico a los grandes medios nacionales, destacó en uno de sus números al grupo de bolivianos que recorría escuelas rurales, o a los profesores chilenos que daban conferencias en los sindicatos, entre otros. ${ }^{31}$ Lo relevante para los medios de comunicación era que el énfasis estaba puesto en el intercambio, los visitantes no sólo conocían las experiencias mexicanas, sino que a su paso iban entregando lo que podían aportar. Esta relación beneficiosa para ambos lados impulsaba las posibilidades de éxito del proyecto cardenista. De igual modo, los visitantes aprovecharían la estadía para sus propios fines propagandísti-

\footnotetext{
${ }^{29}$ Jesús Silva Herzog recorre la experiencia mexicana del intelectual argentino en el prólogo del libro póstumo de Ponce (1938)

${ }^{30}$ En este nivel también cabe considerar los innumerables congresos y reuniones que se organizaron en México. En este tipo de experiencias, la investigación bien podría nutrirse de investigaciones que se detienen en otros periodos históricos (véase el trabajo de Cristina Cárdenas Castillo, 2015).

31 Una de estas giras, la del chileno Manuel Eduardo Hübner, profesor y escritor, no sólo apareció regularmente en los diarios de circulación nacional, sino que se convirtió en libro (Hübner, 1936). Algo que no estuvo lejos de otros casos (Hinojosa, 1935; Kubli, 1935).
} 
cos, como ocurrió en algunos casos durante el connotado Congreso Internacional Indigenista de Pátzcuaro de 1940. Desde un año antes, la embajada de México en El Salvador hacía la advertencia "me permito sugerir a usted que se den los pasos necesarios para evitar que los elementos desafectos al régimen salvadoreño, radicados en México, traten de aprovechar las reuniones científicas de Pátzcuaro para crear problemas". 32

Las giras, en la mayoría de las ocasiones, fueron organizadas directamente por los cónsules o embajadores mexicanos. Pero el interés inicial muchas veces fue compartido, o incluso surgió de las mismas autoridades educativas de los países latinoamericanos. Por ejemplo, en 1936, el Ministerio de Instrucción Pública de Venezuela decidió enviar una misión para conocer cómo se estaban organizando las escuelas rurales. La intención fue bien acogida por la Secretaría de Relaciones Exteriores de México, aunque con el tiempo y los cambios políticos en Venezuela, dictadura mediante, el camino que siguió el proceso fue cada vez más ríspido. ${ }^{33}$ El caso mejor conocido sobre este tipo de intercambios durante el periodo es el de los bolivianos que vinieron a México en 1937. El trabajo de Arturo Vilchis Cedillo, sobre las relaciones establecidas entre ambos países a partir de la experiencia pedagógica de Warisata, se detiene a analizar este proceso. Es interesante cómo el autor destaca los riesgos que corrió el intercambio: "La obstrucción para el envío de los becados a territorio mexicano obedecía al desinterés por parte de las autoridades educativas bolivianas por difundir la obra pedagógica que en Warisata se realizaba, pero principalmente por la presión de los latifundistas y hacendados bolivianos" (Vilchis, 2014: 154).

Finalmente, después de estiras y aflojas, los bolivianos llegaron a México, visitaron los talleres del Departamento de Asuntos Indígenas en el municipio de Ixmiquilpan, observaron algunas cooperativas de producción, internados indígenas, también escuelas regionales campesinas y escuelas rurales. De igual modo, donde llegaban dieron conferencias sobre el problema del indio en Bolivia, con apoyo de películas preparadas para la ocasión. Por supuesto, el intercambio no sólo incluyó a los vinculados a Warisata, también significó la entrega de becas a estudiantes militares y en especial siete cupos para universitarios, relacionados con el petróleo, los cuales fueron sistemáticamente supervisados por las autoridades bolivianas. Por último, en esta cohorte de intercambio, Félix Rojas Ulloa obtuvo una pensión para estudiar pintura en la Escuela Central de Artes Plásticas. ${ }^{34}$ Con esto advertimos la magnitud que este tipo de iniciativas podía llegar a tener, cuando las autoridades coincidían en sus esfuerzos.

\footnotetext{
32 "Organización del Congreso Indigenista Interamericano", 1939-1940, AHSRE, Fondo Asuntos Diplomáticos, exp. III-2363-I, parte IV, sin foliar.

33 "La Legación de Venezuela en México informa a la Secretaría de Relaciones Exteriores que el órgano del Ministerio de Instrucción Pública de Venezuela ha designado una misión de profesores para estudiar en México la organización de las escuelas rurales", 1936-1937, AHSRE, Fondo Asuntos Diplomáticos, expediente III-160-3.

34 "Becas para estudiantes bolivianos", 1937-1938, AHSRE, Fondo Asuntos Diplomáticos, exp. III-2359-3.
} 
De todas maneras, pese a todo el apoyo oficial, los límites burocráticos del Estado mexicano algunas veces jugaron en contra de estas misiones. Si bien las secretarías podían emitir descuentos en los ferrocarriles o facilitar los trámites migratorios, las descoordinaciones eran frecuentes e impactaron negativamente en el buen término o inicio de estos procesos. Por ejemplo, los estudiantes chilenos que participaron en el Congreso de Estudiantes Socialistas realizado en Guadalajara no recibieron los fondos comprometidos y quedaron a la deriva. Otros viajes podían incluso ponerse en riesgo desde sus inicios por los malentendidos entre funcionarios menores. Así le pasó, por ejemplo, a Enrique Coloma Silva, quien venía de Ecuador a estudiar la situación petrolera, especialmente su proceso de exploración, algo que había sorprendido en la mayoría de los países del sur del continente. Sin embargo, las autoridades aduanales se negaban a dejarlo ingresar al país, por lo que se produjo un acelerado intercambio de telegramas entre las autoridades implicadas. ${ }^{35}$

El tema relevante que nos cuestiona esta situación es cómo la presencia de latinoamericanos estudiantes, profesores o propagandistas, se relacionó ya no con el sistema educativo mexicano, sino con el amplio abanico de autoridades estatales, que estuvieron lejos de constituir un espacio monolítico. De igual modo podemos preguntarnos por la inserción de estos extranjeros en la sociedad mexicana en su conjunto, una sociedad que tendía muchas veces a desconfiar de las propuestas externas a sus propios procesos locales.

Antes de concluir este apartado, conviene destacar un elemento que, de alguna manera, ha estado presente a lo largo de las páginas previas: el intercambio tuvo un importante componente orientado no sólo hacia estudiantes o profesores del ámbito universitario, sino también al resto de los niveles educativos. Las giras por lo general estuvieron integradas por maestros; mientras que la Escuela Nacional de Maestros recibía estudiantes y profesores latinoamericanos y el Sindicato de Trabajadores de la Enseñanza de la República Mexicana desarrollaba sus mayores esfuerzos por vincularse con el magisterio a nivel continental. ${ }^{36}$

El Nacional explicaba la doble labor que a su juicio debían realizar los maestros latinoamericanos una vez que llegaran a México: "La docente, propiamente dicha y la de formar a los maestros mexicanos en las ramas de su misma especialidad, aprovechando a los elementos estudiosos que tengan vocación para el magisterio". ${ }^{37}$ Esta duplicidad permitiría a las instituciones mexicanas realizar las labores sociales que el gobierno les encomendaba.

35 "El gobierno de México hizo gestiones ante las autoridades aduanales de Veracruz, que permitieran el desembarco y entrada al país al señor Enrique Coloma Silva, comisionado por el gobierno ecuatoriano para estudiar lo referente al problema petrolero y, en general el desarrollo de la industria minera en México", 1938, AHSRE, Fondo Asuntos Diplomáticos, expediente III-336-13.

36 "El Sindicato de Trabajadores de la Enseñanza de la República Mexicana informa a la Secretaría de Relaciones Exteriores del peligro en el que se encuentra la maestra salvadoreña, Amparo Casanahualpa”, 1939-1940, AHSRE, Fondo Asuntos Diplomáticos, expediente III-414-41.

37 "Otras profesiones llenas de gran sentido social", en El Nacional, 7 de enero de 1938, p. 1. 
Quienes llegaban a México, independientemente a qué disciplina se dedicaran, debían desarrollar una labor pedagógica.

En ese sentido, conviene preguntarnos por el impacto que estos procesos tuvieron no sólo en cada especialidad, sino en el fortalecimiento de la pedagogía en su conjunto. En otras palabras, hasta qué punto una historia del intercambio nos permite penetrar en una historia de la educación en México. La respuesta a esta interrogante es, sin lugar a duda, uno de los aspectos centrales para evaluar de manera eficiente y contextualizada las posibilidades y los límites del intercambio académico de México con los países de América Latina.

\section{A modo de conclusión}

Volviendo al caso de Warisata y su relación con México, cabe subrayar un aspecto sobre el que Arturo Vilchis nos advierte. El único representante del proyecto pedagógico de la Escuela de Warisata, Carlos Salazar, integrante de la misión boliviana, en un principio no estaba dispuesto a viajar a México. Prefería quedarse en su tierra, ya que consideraba que lo mejor para su propio proyecto era "empaparse de la realidad" boliviana. "Sin embargo, el profesor cambió de opinión influenciado por la decisión de la comunidad de Warisata, que a través del Parlamento de Amautas lo persuadió para que cambiara su forma de pensar, y optara por viajar" (Vilchis, 2014: 155), explica el autor. Este caso nos releva la importancia que adquirió el intercambio académico, mucho más allá de los intereses diplomáticos de los propios Estados. Para la comunidad de Warisata, así como muchas otras agrupaciones, sindicatos o individuos, las posibilidades de conocer la experiencia mexicana desde dentro se convirtió en un modo de proyectar sus propios trabajos. Conocer cuán profundo fue este proceso es parte de la agenda de investigación que se propone abrir este artículo.

A lo largo de las páginas previas, en lugar de ofrecer respuestas a problemas agotados, se planteó una serie de preguntas y cuestionamientos que se abordan a través del estudio del intercambio académico. Si en algunos elementos se hizo un énfasis especial, en otras ocasiones se incorporaron de manera tácita debates sobre aspectos relevantes para los historiadores, por ejemplo, las fuentes que permiten reconstruir esta historia. Los archivos diseminados, fragmentarios, son parte sustancial de este rastreo, así como de las experiencias de los estudiantes y profesores. También a nivel de subtexto, se destacó la importancia de las publicaciones como mecanismo de intercambio, pero sin detenerse a analizar todas las implicaciones que esto posee. De igual modo, a lo largo de este trabajo se pondera tácitamente que el acercamiento biográfico cobra una vital importancia como metodología de análisis. Se optó por no profundizar en estos elementos para no distraernos del eje central 
del artículo, que se relaciona, finalmente, con formular una primera caracterización sobre quiénes eran los estudiantes y profesores que llegaron a México y por qué decidieron hacerlo.

Quizás uno de los elementos mencionados que requiere una mayor detención se refiere a la autonomía del campo académico respecto de los intereses políticos y diplomáticos. Como se ha visto, y como lo desarrollan otros autores (Charle et al., 2006), la relación entre el establecimiento de una institucionalidad nacional y los requerimientos transnacionales de las interacciones académicas, a modo de caleidoscopio, implicó la constante reconfiguración de todos los elementos involucrados. Cada uno de los casos fue diferente al anterior, pero manteniendo algunos puntos de contacto mínimos para considerarse parte de un mismo proceso. Por este motivo, la pregunta sobre el intercambio académico no sólo permite analizar el desarrollo de ciertas disciplinas científicas, sino también la relación entre el conocimiento en un sentido amplio del término y los vaivenes de los procesos políticos.

Finalmente, antes de cerrar, me parece necesario recuperar un problema que no fue menor para los implicados en los intercambios. En una carta a Vicente Lombardo Toledano, un grupo de estudiantes latinoamericanos solicitaba su apoyo: "Habiendo cumplido, los compañeros colombianos Heliodoro Guarín y Juan N. Baquero, de manera altamente honrosa el cometido que los trajo a México, y encontrándose ellos carentes de medios para retornar a su país provistos de los elementos indispensables para el buen logro de su misión de propaganda revolucionaria, nos permitimos suplicar a Ud., de la manera más atenta, quiera acordar que la prestigiosa organización obrera que Ud. es su digno secretario General, acuerde una ayuda económica para estos dos compañeros" ${ }^{38}$ La solicitud se realizó en nombre de la solidaridad indoamericana, y nos recuerda que el viaje del intercambio apenas estaba comenzando cuando estos estudiantes y profesores salían de México de regreso hacia sus respectivos países.

\title{
Fuentes
}

\author{
Archivos \\ AGN Archivo General de la Nación, Ciudad de México. \\ Fondo: Dirección de Investigaciones Políticas y Sociales. \\ Fondo: Presidente Lázaro Cárdenas. \\ AHSRE Archivo Histórico de la Secretaría de Relaciones Exteriores, Ciudad de México. \\ Fondo: Asuntos diplomáticos. \\ FHVLT Fondo Histórico Vicente Lombardo Toledano, Universidad Obrera de México, Ciudad de \\ México.
}

Fuentes hemerográficas

38 "Carta de estudiantes latinoamericanos de la Universidad Obrera a Vicente Lombardo Toledano", 8 de enero de 1938, en FHVLT, id. 17557, leg. 306, f. 1. 
Frente a Frente, Ciudad de México, 1936.

El Nacional, Ciudad de México, 1935, 1938, 1939.

El Machete, Ciudad de México, 1936-1937.

Bibliografía

Alfonso, Malena (2015), De huellas, aprendizajes, legados y no retornos. La experiencia de un grupo de pedagogos argentinos en el exilio mexicano (1975-1983), Consejo Mexicano de Investigaciones Educativas-Universidad Pedagógica Nacional, México.

Anónimo [Luciano Kubli] (1935), El ejido en Yucatán, Talleres Gráficos de la Nación, México.

Asfura, Antonio (1941), "Anotaciones al margen de algunos problemas de Derecho Penal", tesis de Licenciatura, Facultad de Derecho y Ciencias Sociales, UNAM, México.

Bazant, Mílada (1987), "Estudiantes mexicanos en el extranjero: el caso de los hermanos Urquidi", Historia Mexicana, vol. 36, núm. 144, pp. 739-758.

Bergel, Martín (2015), El Oriente desplazado. Los intelectuales y los orígenes del tercermundismo en la Argentina, Universidad Nacional de Quilmes, Bernal.

Britton, John A. (1995), Revolution and Ideology. Images of the Mexican in the United States, The University Press of Kentucky, Lexington

Buchenau, Jürgen (1996), In the Shadow of the Giant: The Making of Mexico's Central America Policy, 18761930, The University of Alabama Press, Tuscalusa.

Cárdenas Castillo, Cristina (2015), Viajeros y educación en México. Primera mitad del siglo XIX, Universidad de Guadalajara, Guadalajara.

Carnero Checa, Genaro (1979), Los peces infernales: cuentos, relatos, testimonios, Federación Latinoamericana de Periodistas, México.

Cervo, Amado Luiz (2008), "Relaciones interlatinoamericanas", en Marco Palacios y Gregorio Weinberg (dirs.), Historia General de América Latina. Vol. VIII. América Latina desde 1930, Ediciones UNESCOEditorial Trotta, París, pp. 391-337.

Charle, Christophe, Jürgen Schriewer y Peter Wagner (comps.) (2006), Redes intelectuales trasnacionales. Formas de conocimiento académico y búsqueda de identidades culturales, Ediciones Pomares, México.

De la Peña, Guillermo (1996), "Nacionales y extranjeros en la historia de la antropología mexicana", en Mechthild Rutsch (comp.), La historia de la antropología en México. Fuentes y transmisión, Universidad Iberoamericana-Instituto Nacional Indigenista-Plaza y Valdés, México, pp. 41-81.

Fernández Padilla, Julio (1939), "Concepto del materialismo dialéctico", tesis de licenciatura, Facultad de Derecho y Ciencias Sociales, UNAM, México.

Fierros, Gustavo (2001), Memorial del aventurero. Vida contada de Juan de la Cabada, Conaculta, México.

García Ugarte, Marta Eugenia (2017), Tiempo y memoria: historia del ITAM (1946-2016), t. I, Instituto Tecnológico Autónomo de México, México.

Geoffroy Rivas, Pedro (1937), "Teoría marxista del Estado", tesis de licenciatura, Facultad de Derecho y Ciencias Sociales, UNAM, México.

(2008), El surco de la estirpe. Poesía completa. Estudio introductorio y recopilación Rafael Lara Martínez, Dirección de publicaciones e impresos, San Salvador.

Gleizer, Daniela (2011), El exilio incómodo. México y los refugiados judios. 1933-1945, El Colegio de MéxicoUniversidad Autónoma Metropolitana/Cuajimalpa, México.

González Marín, Silvia (1984), "La universidad frente al Estado cardenista", Memorias del primer encuentro de historia sobre la universidad, CESU/UnAM, México, pp. 154-163.

Granados, Aimer (2007), "La corriente cultural de la Jae en México: el Instituto Hispano Mexicano de Intercambio Universitario, 1925-1931", Revista de Indias, vol. LXVII, núm. 239, pp. 103-124. 
Hernández García, José Ángel (2012), "La influencia pedagógica del exilio republicano español: la edad de oro de la enseñanza en Colombia", Latinoamérica, vol. 54, pp. 135-153.

Herrera León, Fabian (2009), "México y el Instituto Internacional de Cooperación Intelectual, 1926-1939", Tzintzun. Revista de Estudios Históricos, núm. 49, enero-junio, pp. 169-200.

Hinojosa, Roberto (1935), El Tabasco que yo he visto, Talleres gráficos de la Oficina de publicaciones y propaganda de la Secretaría de Agricultura y Fomento, México.

Hübner, Manuel Eduardo (1936), México en marcha, Zigzag, Santiago.

Izquierdo y de la Cueva, Ana Luisa y Elaine Day Schele (2015), "Alberto Ruz Lhuillier. Más allá del descubrimiento de la tumba del Templo de las Inscripciones de Palenque. Militancia política y arqueología maya", Estudios de Cultura Maya, vol. 46, documento html disponible en: <https:// revistas-filologicas.unam.mx/estudios-cultura-maya/index.php/ecm/article/view/719/727>. (fecha de consulta: 13/11/2017)

Kiddle, Amelia M. (2016), Mexico's Relations with Latin America during the Cárdenas Era, University of New Mexico Press, Albuquerque.

Latapi Sarre, Pablo (coord.) (2003), Un siglo de educación en México, 2 ts., Fondo de Estudios e Investigaciones Ricardo J. Zevada-Conaculta-Fondo de Cultura Económica, México.

Loyo, Engracia (1984), "Lectura para el pueblo, 1921-1940", Historia Mexicana, vol. 33, núm. 3, pp. 298 345.

Marichal, Carlos (2002), México y las conferencias panamericanas, 1889-1938. Antecedentes de la globalización, Secretaría de Relaciones Exteriores, México.

Melgar Bao, Ricardo (2003), Redes e imaginario del exilio en México y América Latina, 1934-1940, Ediciones Libros en Red, Buenos Aires.

Minor, Adriana (2016), "Traducción e intercambios científicos entre Estados Unidos y Latinoamérica: el Comité Inter-americano de Publicación Científica (1941-1949)", en Mateos, Gisela y Edna SuárezDíaz (comps.), Aproximaciones a lo local y lo global: América Latina en la Historia de la Ciencia contemporánea, Centro de Estudios Filosóficos, Políticos y Sociales Vicente Lombardo Toledano, México, pp. 183-214.

Padua, Jorge (2003), "La educación en las transformaciones sociales", en Latapi Sarre, Pablo (coord.), Un siglo de educación en México, 2 ts., Fondo de Estudios e Investigaciones Ricardo J. ZevadaConaculta-Fondo de Cultura Económica, México, pp. 84-149.

Piñera, David (coord.)(2011), La Revolución Mexicana y las universidades estatales pionera 1917-1925, Universidad Autónoma de Baja California-Red de Historia de la Universidades Estatales de México, Mexicali, Baja California.

Pita González, Alexandra (2014), Educar para la paz. México y la cooperación intelectual internacional, 1922-1948, Universidad de Colima-Secretaría de Relaciones Exteriores, México.

Ponce, Aníbal (1938), Dos hombres: Marx, Fourier, Fondo de Cultura Económica, México.

Pulido, David Antonio (2017), "El papel del Congreso Local Estudiantil en las iniciativas de unidad latinoamericana del Constitucionalismo (1916-1918)", Latinoamérica, vol. 65, pp. 133-169.

Rangel Guerra, Alfonso (1983), La educación superior en México, El Colegio de México, México.

Reggiani, Andrés H. (2007), "De rastacueros a expertos. Modernización, diplomacia cultural y circuitos académicos transnacionales, 1870-1940", en Ricardo D. Salvatore (comp.), Lugares del saber. Contextos locales y redes transnacionales en la formación del conocimiento, Beatriz Viterbo Editora, Rosario.

Rivera Mir, Sebastián (2018), Militantes de la izquierda latinoamericana en México 1920-1934. Prácticas políticas, redes y conspiraciones, El Colegio de México-Secretaría de Relaciones Exteriores, México.

(2012), "La experiencia de los centroamericanos becados en México (1922-1928). Entre carencias, vida académica y propaganda revolucionaria", Latinoamérica, vol. 55, pp. 185-241. 
Ruz, Alberto (1936), "La enseñanza política de la experiencia cubana", Frente a Frente, núm. 1, marzo, pp. $16-17$.

Salvatore, Ricardo D. (2016), Disciplinary Conquest. U.S. Scholars in South America, 1900-1945, Duke University Press, Durham y Londres.

Salvatore, Ricardo D. (comp.) (2007), Lugares del saber. Contextos locales y redes transnacionales en la formación del conocimiento, Beatriz Viterbo Editora, Rosario.

Schötler, Peter (2006), "Redes de historiadores franceses y alemanes: el caso de los primeros Annales", en Christophe Charle, Jürgen Schriewer y Peter Wagner (comps.), Redes intelectuales trasnacionales. Formas de conocimiento académico y búsqueda de identidades culturales, Ediciones Pomares, México. Vilchis Cedillo, Arturo (2014), "La Escuela-Ayllu de Warisata, Bolivia y sus relaciones con México", en De Raíz Diversa, vol. 1, núm. 1, abril-septiembre, pp. 145-170.

Yankelevich, Pablo (2003), La revolución mexicana en América Latina: Intereses políticos e itinerarios intelectuales, Instituto Mora (Colec. Historia Internacional), México.

Zuleta, María Cecilia (2008), Los extremos de Hispanoamérica: relaciones, conflictos y armonías entre México y el Cono Sur, 1821-1990, Secretaría de Relaciones Exteriores, México.

Sebastián Rivera Mir es Doctor en Historia por El Colegio de México e investigador en El Colegio Mexiquense. Sus principales líneas de investigación son historia de la edición en México durante el siglo Xx, historia del intercambio académico en México e historia de la izquierda latinoamericana en la primera mitad del siglo xx. Sus últimas dos publicaciones son Militantes de la izquierda latinoamericana en México, 1920-1934, El Colegio de México/Secretaría de Relaciones Exteriores, México (en prensa), y "El expendio de libros de viejo en la ciudad de México (1886-1930). En busca de un lugar entre pájaros, fierros y armas", Información, cultura y sociedad, núm. 36 (junio de 2017), pp. 43-64.

Recibido: 23 de noviembre de 2017

Aceptado: 7 de mayo de 2018 